\title{
PWM Based VSC for Power Quality Assessment of Grid Integrated DFIG-WECS
}

\author{
M.A Soomro ${ }^{1 *}$, Z.A Memon ${ }^{2}$, M. Kumar ${ }^{3}$ \\ ${ }^{1}$ Assistant Professor, Department of Electrical Engineering, \\ Mehran University of Engineering and Technology, Jamshoro, 76090, PAKISTAN \\ ${ }^{2}$ Professor, Department of Electrical Engineering, \\ Mehran University of Engineering and Technology, Jamshoro, 76090, PAKISTAN \\ ${ }^{3}$ Associate Professor, Department of Electrical Engineering, \\ Mehran University of Engineering and Technology, Jamshoro, 76090, PAKISTAN \\ *Corresponding Author
}

DOI: https://doi.org/10.30880/ijie.2020.12.06.027

Received 20 February 2020; Accepted 19 July 2020; Available online 02 July 2020

\begin{abstract}
The socioeconomic indicators are exclusively dependent upon the growth of energy for every country. The rise of population and urbanization on one hand and environmental degradation by fossil fuel sources on the other has realized the world for sustainable sources of energy to meet the energy imbalance. Therefore, high penetration of wind energy is need of the hour to meet the challenge of rising consumption of power. Globally, wind energy trends are witnessing a rapid growth with the passage of time. In this research contribution, the Doubly Fed Induction Generator (DFIG) derived wind power generation has been selected to harness wind energy at variable speed. The uncertain and fluctuating nature of wind flow cause power quality problems. MATLAB simulation model has been designed and response of power quality issues like voltage sag and harmonic distortion is checked both at No load and with load at the point of common coupling (PCC). For smooth integration of wind turbine generator with power grid, pulse width modulated (PWM) voltage source converters (VSC) are used both at the rotor side converter (RSC) and the grid side converter (GSC). Proportional integral (PI) controllers are used along with VSC for high power output.
\end{abstract}

Keywords: Power Quality, DFIG, Point of common coupling, Voltage Source Converter, PI Controller

\section{Introduction}

The world is experiencing wind energy with high penetration causing multifold increase in the wind energy capacity [1]. The wind energy conversion system (WECS) not only aims at maximizing the power at variable wind speeds but it should also provide good power quality [2]. Typically, due to its elegant performance with variable wind speeds, partial scale convertors, effective active and reactive power transfer and control capacities, low equipment costs and reduced power losses, DFIG has been chosen to maintain maximum power output [3]. It covers more than $50 \%$ of worldwide onshore large-scale wind power installations [4], [5].

The main problem with WECS on a converter basis is that frequency and voltage variations [6-7] are driven by the variable wind speed. Large oscillations in wind speed as stated above significantly change the power output as a result of irregular environmental conditions [8]. For the operational efficiency and reliability, DFIG based wind power generation must be capable of staying with power grid and contribute towards voltage stability. Since, DFIG uses a bidirectional VSC which enables it to receive and transfer reactive power [9-10]. 
The existing literature on grid integrated DFIG is given as follows; The operation of grid integrated DFIG under balanced conditions was investigated in [11]. Power quality issues of grid integrated DFIG were discussed in [12]. It highlights that the high penetration of wind energy becomes source of increased percentage of total harmonic distortion (THD). A synchronous generator (SG) and DFIG identified in [13] provided an analysis of the power quality of WECS linked to the power system network under conditions of a variable wind speed. In [14] the rotor overvoltage reaction was studied in wind generation based on DFIG. The study examined the effects of one voltage drop event on voltage, phase angle jump (PAJ), and the point on the wave (POW). The effects of DFIG penetration, small signal and transient stability were investigated in [15]. The wind energy with high penetration became source of sustained oscillations in the WECS. The voltage stability of power grid with high penetration of wind energy was discussed in [16]. It analysed the active power for the determination of limits of stability in voltage keeping in view maximum load ability limit to guarantee the generated power.

This paper analyses the effect of fluctuations / oscillations in case of variable wind speed on electrical power output. Moreover, transient conditions due to variation in supply voltage have been considered. PWM based voltage source converters have been used along with conventional PI controllers both at RSC and GSC. To avoid the error in the magnitude and the phase angle, phase locked loop (PLL) has been used to maintain synchronization with power grid. The oscillations in the grid integrated wind power system is in-built phenomenon thus affecting power system stability. The wind power output is considerably affected due to load changes. Consequently, power quality analysis of grid integrated DFIG based wind generator has been done both at no load and with load operating conditions so that secure power supply may be achieved.

\section{Modeling of wind turbine and DFIG}

The wind turbine consists of multistage gearbox attached to the turbine blades and the rotor hub. The kinetic energy of wind velocity is converted through the wind turbine shaft into mechanical energy. To transform mechanical energy into electrical output, the shaft drives the induction rotor or synchronous generator. The coefficient of performance $(\mathrm{Cp})$ determines the power output of wind energy. $\mathrm{Cp}$ is higher at rated wind speed i.e. $12 \mathrm{~m} / \mathrm{s}$ to $16 \mathrm{~m} / \mathrm{s}$. At rated wind speed, the DFIG is responsible to generate constant power output. The characteristics curve of Cp is depicted in fig. 1.

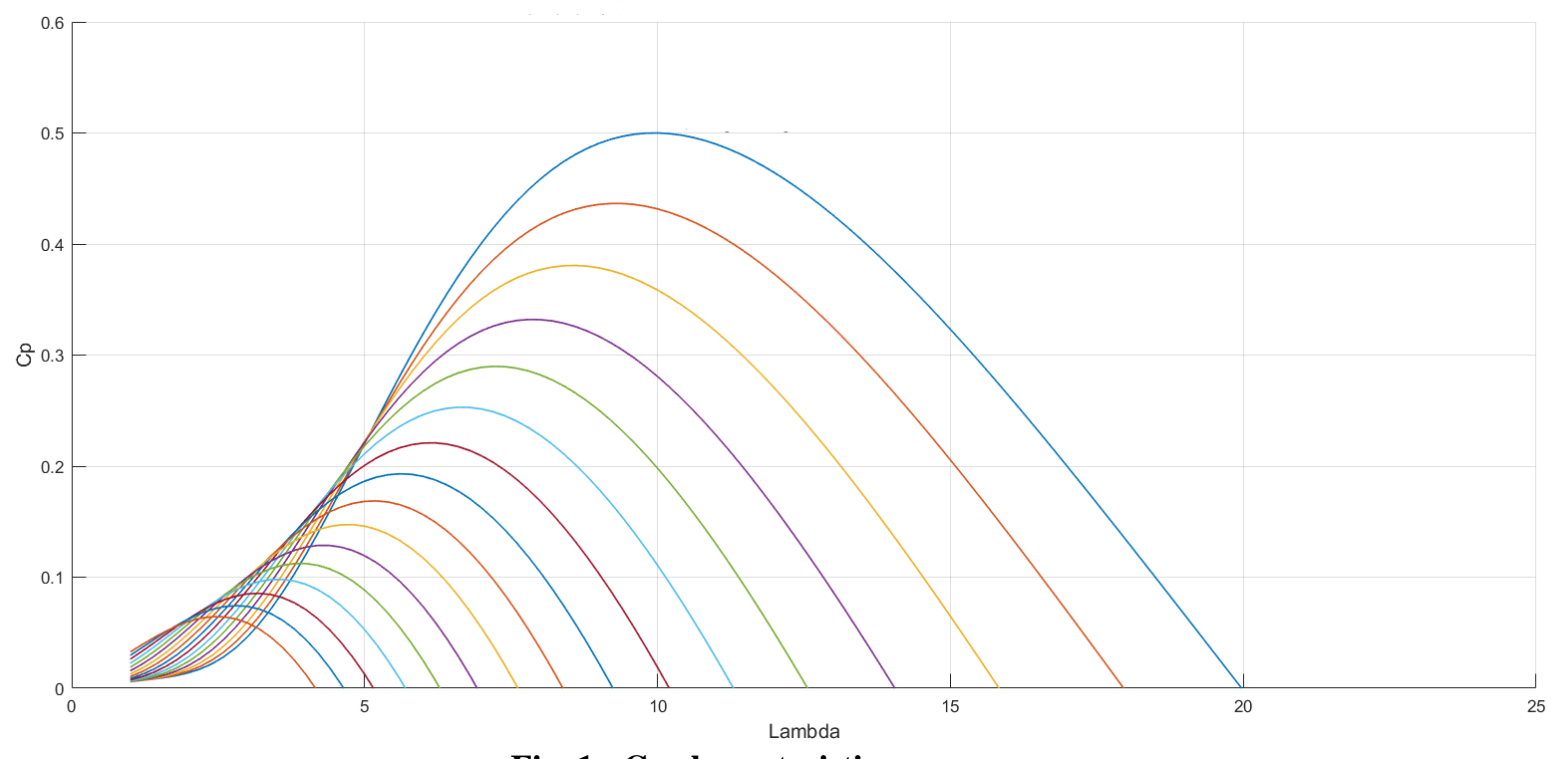

Fig. 1 - Cp characteristics curve

\subsection{Wind Turbine Model}

The aerodynamic power of wind turbine through radius $\mathrm{R}$ is expressed as:

$$
P_{w}=\frac{1}{2} \rho \pi R^{2} v_{w}^{3}
$$

The mechanical power $\mathrm{P}_{\mathrm{t}}$ depends upon the power coefficient $C_{p}(\lambda, \beta)$. It can be expressed as;

$$
P_{t}=\frac{1}{2} C_{p}(\lambda, \beta) \rho \pi R^{2} v_{w}^{3}
$$

A wind turbine is only limited by the possibility of converting only a fixed percentage of the wind energy it captures under the Betz law. This percentage is shown by a $\mathrm{Cp}$ which depends on wind velocity, turbine velocity and blade 
angle ( $\beta$ ). The angle of the blade can be adjusted using the pitch controller and the tip speed ratio (TSR). Moreover, TSR may be expressed by relation;

$\lambda=\frac{\text { Tip speed of blade }}{\text { wind speed }}=\frac{\omega R}{v}$

Where, turbines rotational speed is denoted by ' $\omega$ ' and radius of the turbine blades by ' $R$ '. Thus, The TSR is controllable by the rotational speed of the wind generator.

The maximum theoretical power coefficient value is given by betz limit;

$$
P_{\text {max }}=0.3644 \pi R^{2} v_{w}^{3}
$$

\subsection{DFIG Model}

A simple mathematical model helps analyze the complicated system's behavior in a variety of operating conditions and apply different control strategies. Dynamic model for a DFIG consists of the quantities of direct and quadrature axes (d-q axes) in a synchronous reference frame. The mathematical model of DFIG is expressed in the following terms;

A. The stator and rotor voltages in the d-q reference frame are given as;

B.

$$
\begin{aligned}
& V_{d s}=R_{s} I_{d s}+\frac{d \lambda_{d s}}{d t}-\omega_{s} \lambda_{q s} \\
& V_{q s}=R_{s} I_{q s}+\frac{d \lambda_{q s}}{d t}+\omega_{s} \lambda_{d s} \\
& V_{d r}=R_{r} I_{d r}+\frac{d \lambda_{d r}}{d t}-\left(\omega_{s}-\omega\right) \lambda_{q r} \\
& V_{q r}=R_{r} I_{q r}+\frac{d \lambda_{q r}}{d t}+\left(\omega_{s}-\omega\right) \lambda_{d r}
\end{aligned}
$$

where, $\mathrm{V}, \mathrm{I}, \lambda$ are voltage, current and flux vectors respectively. The subscript ' $\mathrm{s}$ ' and ' $r$ ' refer to the stator and rotor of the DFIG in the d-q reference frame. $R_{s}$ and $R_{r}$ are the stator and rotor resistances respectively. Whereas, $\omega_{s}$ is the stator electrical frequency.

The stator and rotor fluxes related to the respective current are given in the following equations;

$$
\begin{aligned}
& \lambda_{d s}=L_{s} I_{d s}+L_{m} I_{d r} \\
& \lambda_{q s}=L_{s} I_{q s}+L_{m} I_{q r} \\
& \lambda_{d r}=L_{r} I_{d r}+L_{m} I_{d s} \\
& \lambda_{q r}=L_{s} I_{q r}+L_{r} I_{q s}
\end{aligned}
$$

Where $L_{s}, L_{r}, L_{m}$ denotes to the stator, rotor and the magnetizing inductance respectively.

The stator active and reactive powers in terms of stator d-q current and voltage are expressed as follows;

$$
\begin{aligned}
& \boldsymbol{P}_{s}=\frac{3}{2}\left(\boldsymbol{V}_{d s} \boldsymbol{I}_{d s}+\boldsymbol{V}_{q s} \boldsymbol{I}_{q s}\right) \\
& \boldsymbol{Q}_{s}=\frac{3}{2}\left(\boldsymbol{V}_{\boldsymbol{q} s} \boldsymbol{I}_{d s}-\boldsymbol{V}_{\boldsymbol{d s}} \boldsymbol{I}_{\boldsymbol{q} s}\right)
\end{aligned}
$$




\section{Working of grid integrated DFIG}

The WECS includes a DFIG with directly connected stator winding and indirectly connected rotor winding via slip rings and carbon brushes to the power grid. This design enables DFIG to shift rotor power at variable speed using a partial scale converter (25-30\%) to capture maximum energy [17], [18]. For smooth integration back to back power electronic converters i.e. RSC and GSC are used in it. As an energy storage feature, the DC link voltage limits voltage changes to a lower value in the rotor winding [19].

Fig.2 exhibits the simplified block diagram of DFIG based WECS. DFIG uses a bidirectional converter which enables it to operate at various operating modes i.e. sub-synchronous, synchronous and super-synchronous mode for the exchange of reactive power to or from the power grid [20]. Additionally, the gearbox is applied to convert the low wind turbine speed into a compatible power frequency, increasing the rotor speed required by the generator to achieve high output power. Though Direct drive technology is also used, yet gear box is dominant over it at continuously varying wind speeds.

The DFIG involves complex control system than that of induction generator. PI controller is applied for maximum power output at varying wind speed. In this case, RSC controller is used for adjusting the DFIG parameters like speed, torque and active power. Whereas, GSC controller upholds constant DC link voltage, high power factor, reactive power injection and DFIG synchronization with the power grid [21-23].

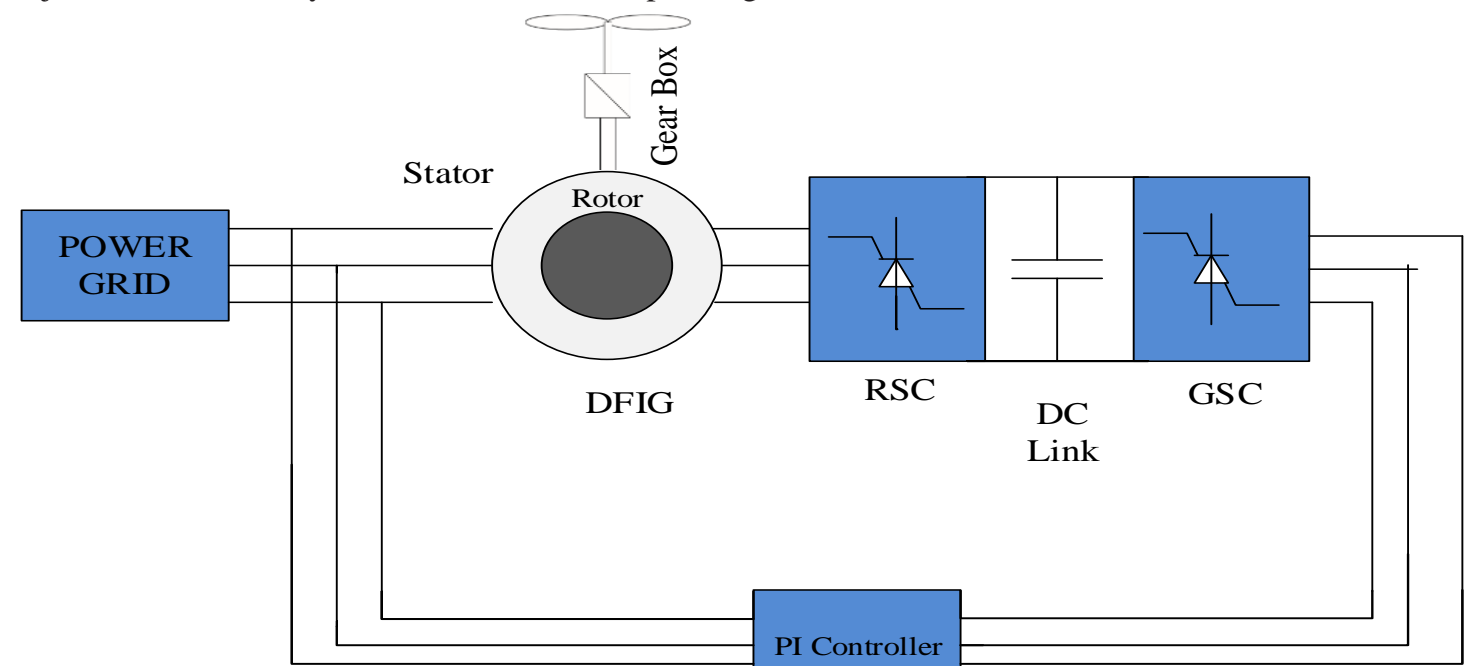

Fig. 2 - Block diagram of DFIG based WECS

\section{Power Quality Assessment}

In recent years, issues with power quality have become more serious with the expansion of the electricity market and the high penetration of wind energy [24]. Therefore, a safe, stable and uninterrupted source of energy, regardless of many uncertainties, is difficult to maintain [25]. Then, it becomes inevitable to investigate the power quality (PQ). Major PQ problems include voltage sag, voltage swell, voltage flicker, harmonic distortion, and voltage imbalance [26]. Wind power generation is very sensitive to load changes. As a result, negative consequences arise, such as disconnection of WTG from grid, loss of power generation and stability of the power system. These severe concerns can intervene with the interconnection of the WECS and the grid [27-28].

\section{Results and Discussion}

MATLAB Simulink version 2018a is used for simulating grid-integrated DFIG model. Table 1. Displays the parameters in the model. 
Table 1 - Simulation Parameters

\begin{tabular}{|c|c|c|c|}
\hline Parameters & Magnitude & Parameters & Magnitude \\
\hline \multicolumn{2}{|c|}{ DFIG } & $\mathrm{V}_{1}$ & $33 \mathrm{kV}$ \\
\hline Frequency & $50 \mathrm{~Hz}$ & $\mathrm{~V}_{2}$ & $575 \mathrm{~V}$ \\
\hline Phase Angle & 120 & \multicolumn{2}{|c|}{ Three Phase Transformer $T_{2}$} \\
\hline No of poles & 03 & Mode of Connection & Yg-D11 \\
\hline Vs & $575 \mathrm{~V}$ & Type of Transformer & Three Phase Core type \\
\hline Rs, Ls & 0.023 p.u, 03 p.u & Nominal Power & 47 MVA \\
\hline $\mathrm{Rr}, \mathrm{Lr}$ & 0.016 p.u, 0.16 p.u & $\mathrm{V}_{1}$ & $132 \mathrm{kV}$ \\
\hline $\mathrm{Lm}$ & 2.9 p.u & $\mathrm{V}_{2}$ & $33 \mathrm{kV}$ \\
\hline Inertia constant $(\mathrm{H})$ & 04 & \multicolumn{2}{|c|}{ PI Controller } \\
\hline DC Bus Capacitor & $20 \mathrm{mF}$ & $\begin{array}{c}\text { DC bus voltage regulator } \\
\text { gains }\end{array}$ & $\mathrm{K}_{\mathrm{p}}=0.05, \mathrm{~K}_{\mathrm{i}}=4$ \\
\hline \multicolumn{2}{|c|}{ Three Phase Transformer $\mathbf{T}_{1}$} & RSC current regulator gains & $\mathrm{K}_{\mathrm{p}}=0.6, \mathrm{~K}_{\mathrm{i}}=8$ \\
\hline Mode of Connection & $\mathrm{D} 11, \mathrm{Yg}$ & GSC current regulator gains & $\mathrm{K}_{\mathrm{p}}=0.83, \mathrm{~K}_{\mathrm{i}}=5$ \\
\hline Type of Transformer & Three Phase Core type & Speed Regulator gains & $\mathrm{K}_{\mathrm{p}}=3, \mathrm{~K}_{\mathrm{i}}=0.6$ \\
\hline
\end{tabular}

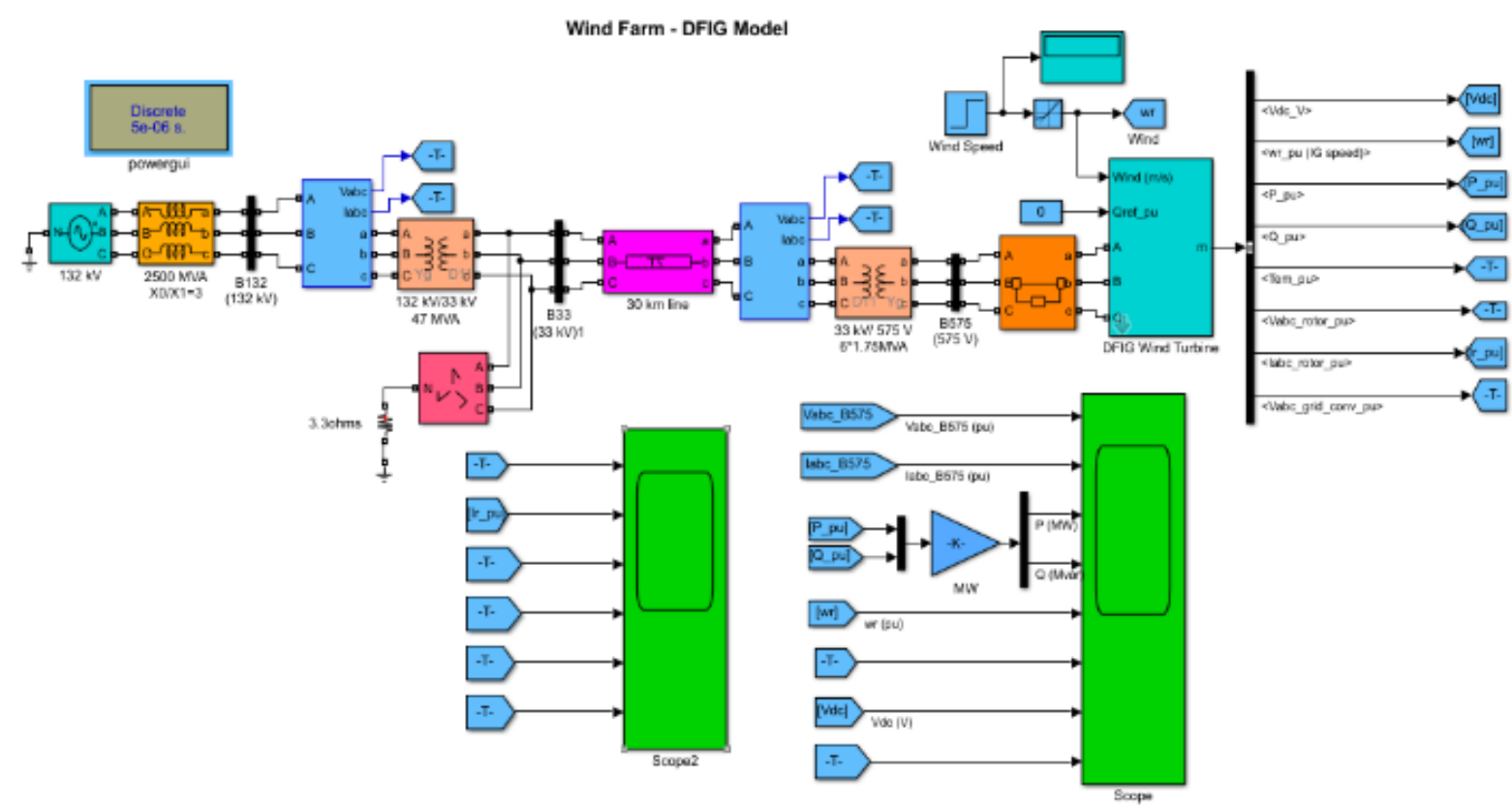

Fig. 3 - MATLAB Simulation model of grid integrated DFIG

The DFIG based wind farm, including six $1.5 \mathrm{MW}$ (WTG) wind generators, is coupled to the $132 \mathrm{kV}$ power network via $30 \mathrm{~km}$ power transmission line and $33 \mathrm{kV}$ step-by-step transformer, as shown in fig. 3. The power quality analysis under different operating conditions is discussed as follows;

\section{Scenario: 1}

According to fig. 4 (a) sudden rise or jerk in the wind gust causes the disturbance in the wind turbine which increases the rotor speed up to $1.3 \mathrm{pu}$ at $0.3 \mathrm{sec}$. Later on, wind speed progressively declines which lowers the rotor speed to 1.03 pu. Fig. 4 (b) describes the electromagnetic torque. As torque and speed are inversely related to each other, therefore, fall in torque at $0.05 \mathrm{sec}$ takes place. The oscillations at $0.1 \mathrm{sec}$ suggests the event of wind gust. Afterwards, torque value increases at $0.35 \mathrm{sec}$ for a momentary period and falls down till it maintains the steady state value at $0.6 \mathrm{sec}$. Fig. 4(c) and 3(d) shows the stator voltage and current respectively. Since, DFIG based WTG is unloaded, therefore the wind gust results in increase of the stator voltage from $1.0 \mathrm{pu}$ to $1.1 \mathrm{pu}$. This disturbance is termed as Power quality problem in terms of voltage swell for momentary period from $0.02 \mathrm{sec}$ till $0.08 \mathrm{sec}$ causing a 
transient stability problem. Due to non-linear behavior of AC supply, the rise in voltage during the starting condition will subsequently cause fall in the current. The stator current is minimized to zero during the disturbance. Consequently, low torque of the WTG is responsible for the disconnection of the DFIG from the power grid.

After disturbance is over, high overcurrent if prolonged may cause excessive heating and damage of power electronic converters of the rotor winding. Moreover, voltage sag event from 0.2 to $0.5 \mathrm{sec}$ (hence overcurrent in stator winding) also occur. Therefore, DFIG should help restore the supply voltage by supplying reactive power from the grid to compensate for the voltage drop of the stator and rotor. In the normal operating conditions, voltage sag event is greater than 0.9 pu. Fig. 4(e) and (f) shows the rotor voltage and current respectively. The results show that rotor voltage rises as voltage swell soon after the wind gust ends. The sharp increase in current and phase imbalance occur in the rotor winding thereby affecting the power quality of wind power unit. The change in current in the rotor winding is higher than that of stator current. Fig. 4 (g) shows the destructive over voltage in DC link voltage to $2000 \mathrm{~V}$ which is beyond its nominal voltage of $1150 \mathrm{~V}$ for the period 0.08 to $0.32 \mathrm{sec}$ and then stabilizes to nominal value. Such rise in voltage may cause the failure of DC bus capacitor which in turn damage the PWM voltage source converter if it persists for several seconds DFIG may be disconnected from the grid.

Fig. 4 (h) and 3 (i) show the active and reactive power for DFIG. During the disturbance active and reactive power shows zero output. As the disturbance is over at $0.08 \mathrm{sec}$, the active power rises and less reactive power is absorbed for magnetization by the rotor from the power grid. During normal operation, the fluctuations in the DFIG power output is due to the wind gust. The active power remains stable to its nominal value $10 \mathrm{MW}$ from $0.1 \mathrm{sec}$ to $0.3 \mathrm{sec}$ and then reduces in the second instant due to the fall in rotor speed and hence the stator voltage. The power fluctuation for long time interval may show adverse effects on wind power unit i.e. deterioration of power quality. Apart from it, the PCC is largely affected by the disturbances. In the unloaded condition, minimum voltage drop occur because DFIG injects reactive power from the grid. In fig. (j) voltage rises from $0.01 \mathrm{sec}$ to $0.08 \mathrm{sec}$. Such adverse situation affects the performance of wind power generation thereby reducing the power quality. On the other hand, the power grid as shown in fig. (k) operates at large voltage $132 \mathrm{kV}$; therefore, it is not considerably affected by the wind gust.

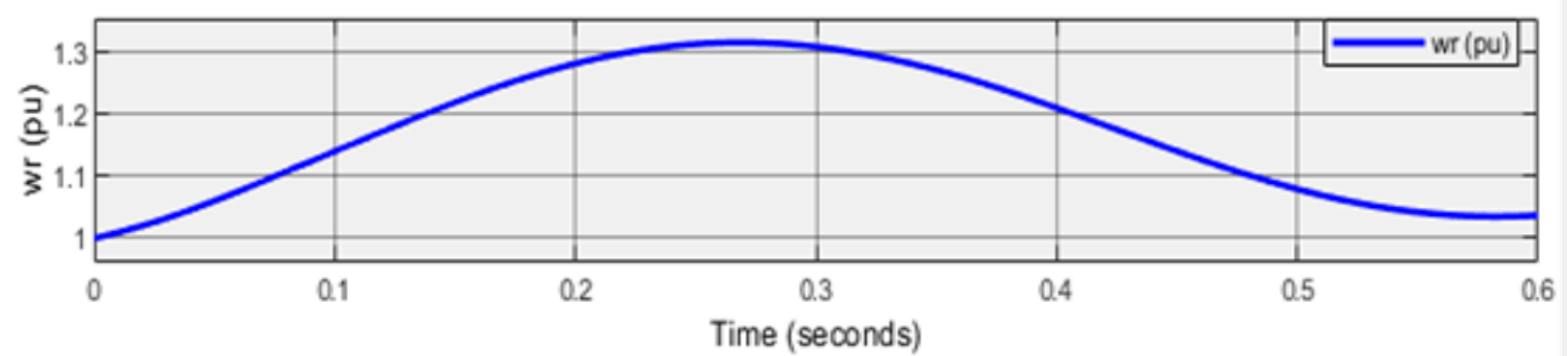

(a) Rotor Speed (pu)

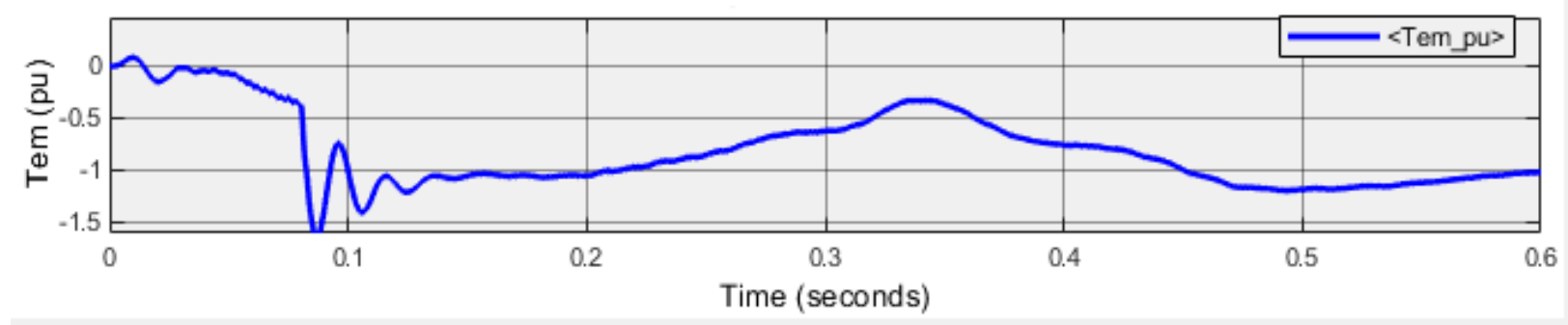

(b) Electromagnetic Torque (pu)

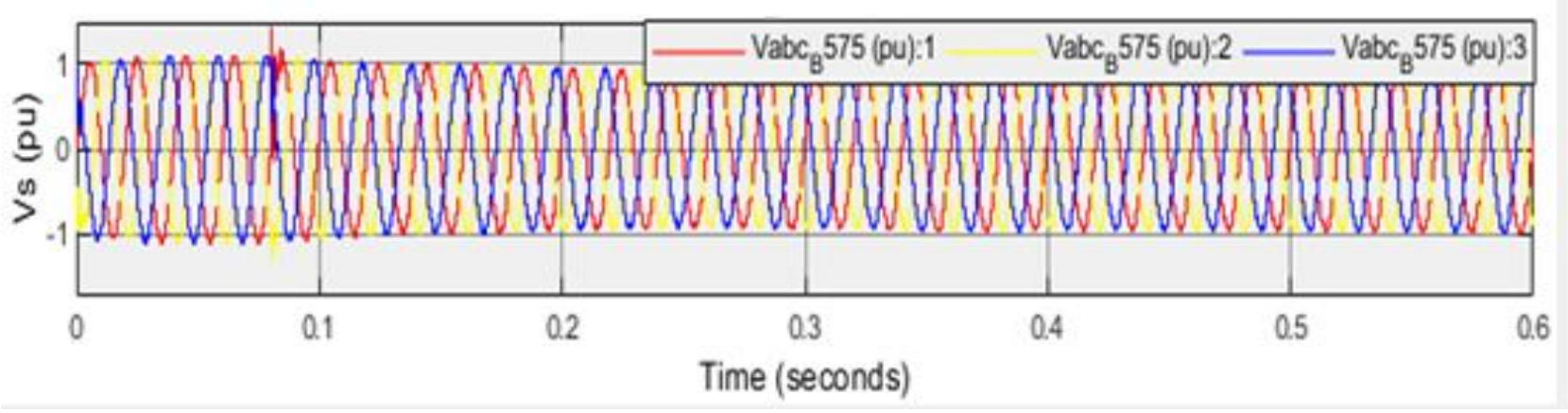

(c) Stator Voltage (pu) 


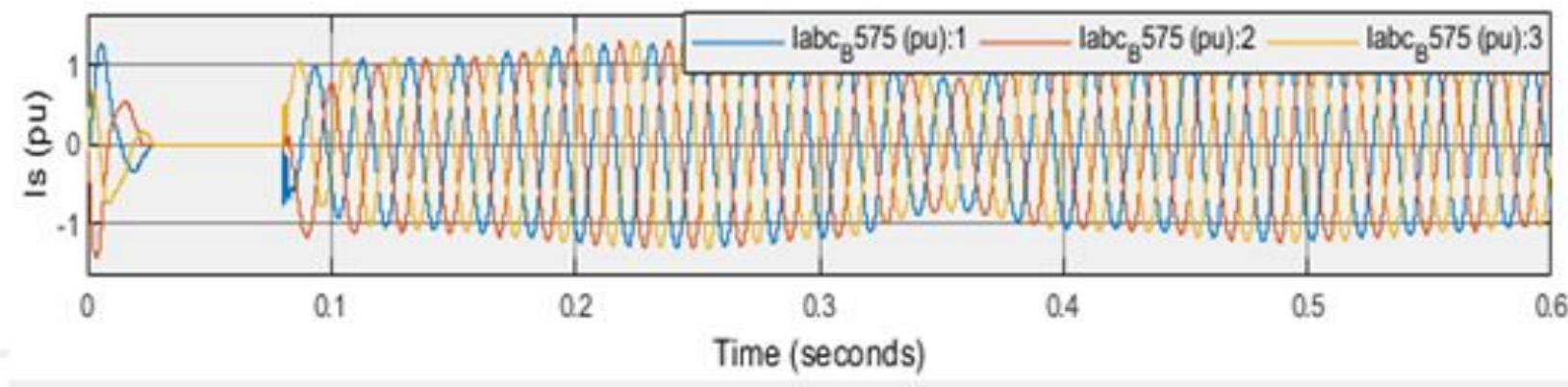

(d) Stator Current (pu)

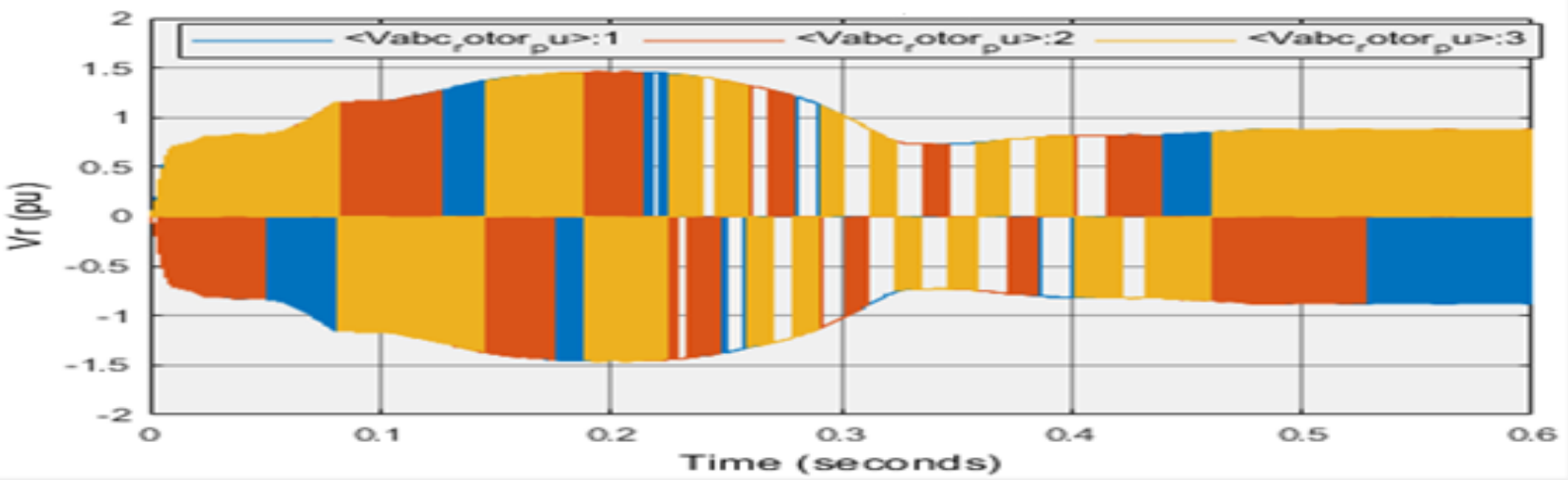

(e) Rotor Voltage (pu)

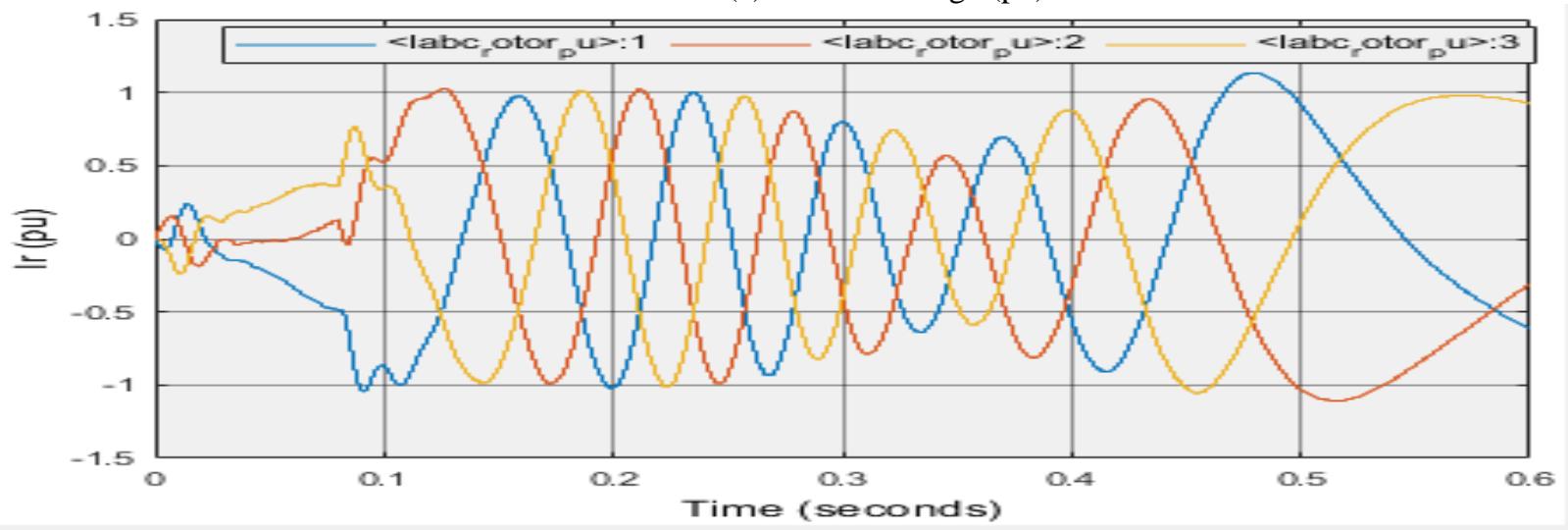

(f) Rotor Current (pu)

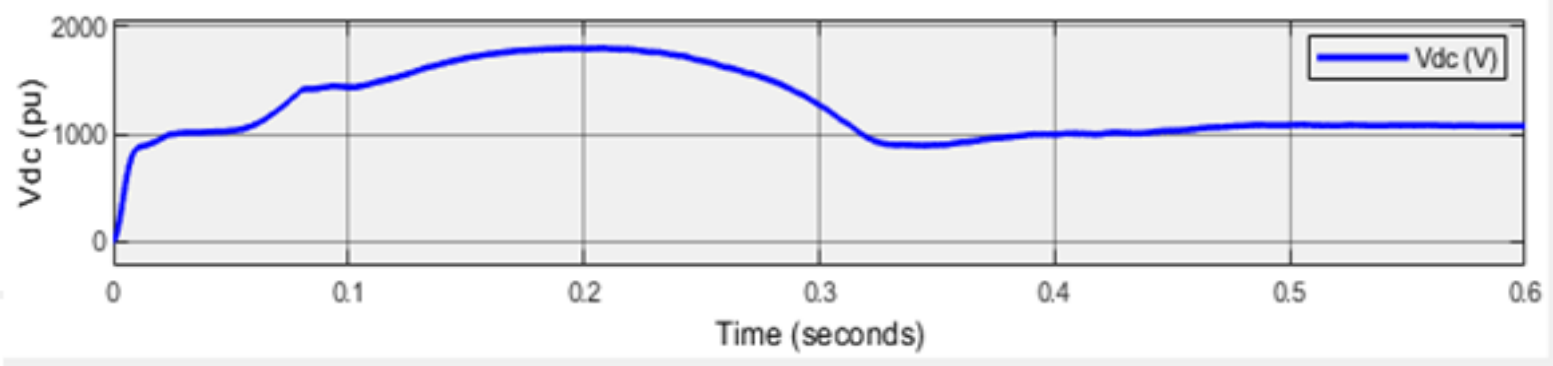

(g) DC link voltage (V) 


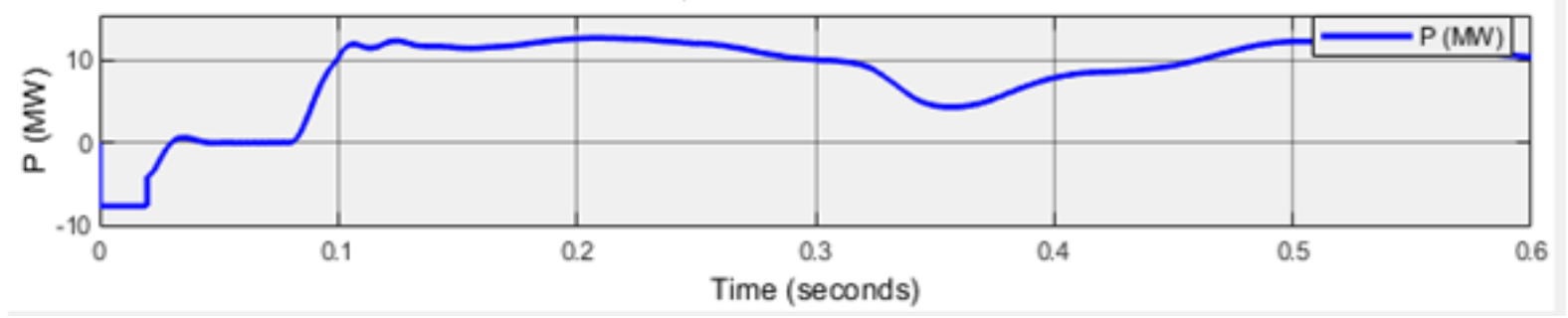

(h) Active Power (MW)

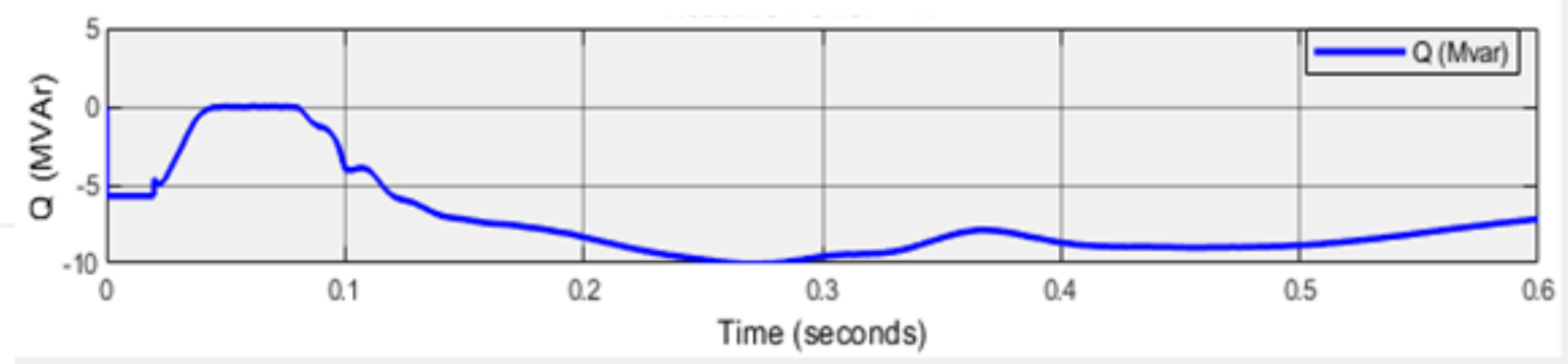

(i) Reactive Power (MVAr)

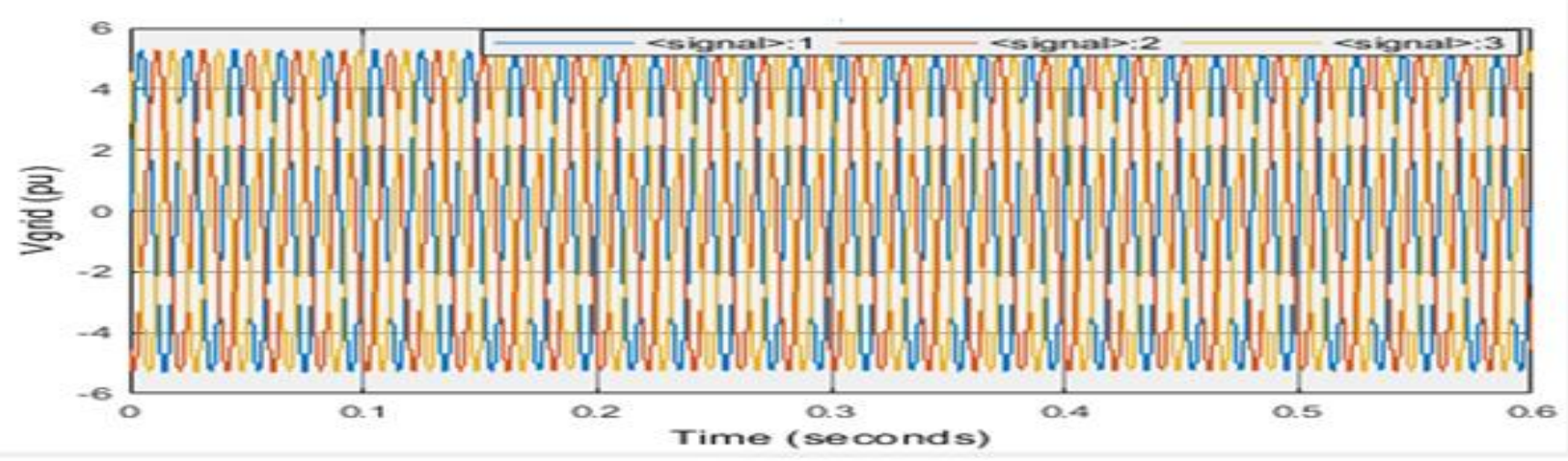

(j) Terminal Voltage at PCC (pu)

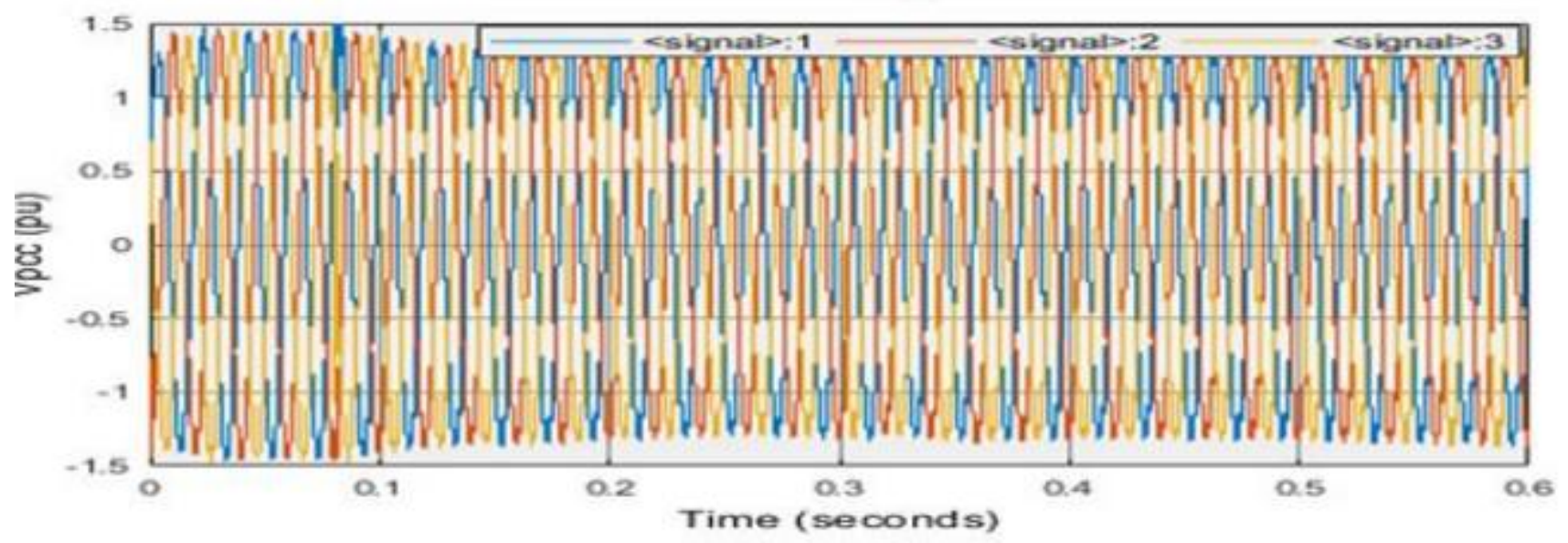

(k) Grid Voltage (pu)

Fig. 4 - Behavior of grid integrated DFIG model at No Load 
The MATLAB simulation has been done in grid integrated DFIG based WECS as depicted in fig. 5. The results obtained from the model have been discussed in the subsequent sections.

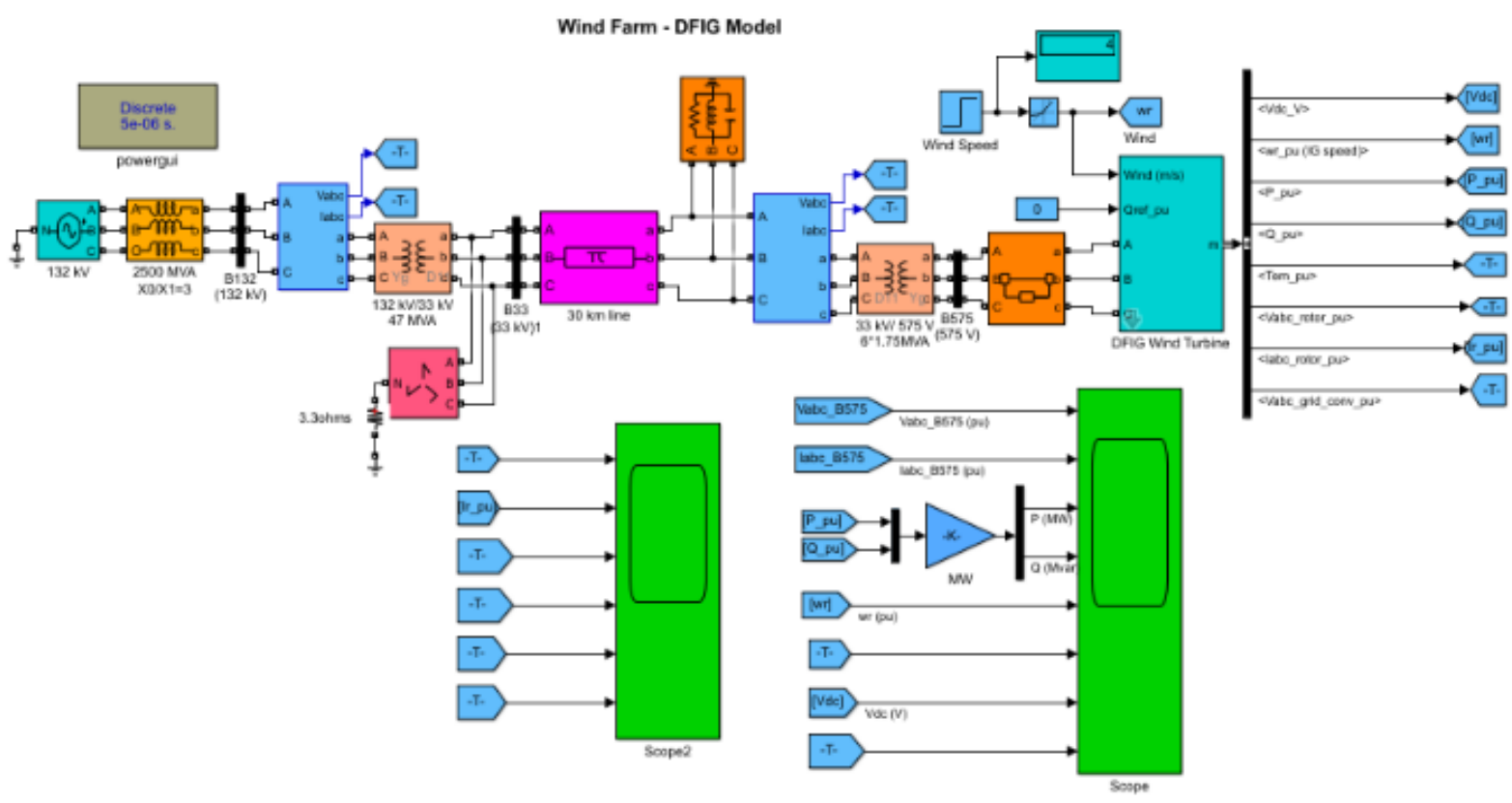

Fig. 5 - MATLAB simulation model of grid integrated DFIG under loading condition at PCC

\section{Scenario: 2}

When $100 \mathrm{~kW}$ load is connected to grid integrated DFIG at PCC, the rotor speed as well as electromagnetic torque are no longer different when compared with unloaded operating condition as shown in fig. 6 (a) and 6 (b). However, the RLC load disturbed the magnitude of voltage which remained less than 1 p.u but interestingly voltage variation is very small. Fig. 6(c) and 6(d) shows the stator voltage and current respectively. The voltage sag occurs during the disturbance period and then sharp overshoot takes place when the disturbance of wind gust is over at 0.08 sec. Due to non-linear behavior of AC supply voltage, the stator current becomes disturbed and is minimized to zero. The stator current is significantly reduced during fall of wind speed from $0.35 \mathrm{sec}$ to $0.5 \mathrm{sec}$. During this activity, low torque may force the DFIG to detach from the power grid.

When disturbance is over, high overcurrent in stator winding has been observed which may cause excessive heating and damage VSC. Fig. 6 (e) and 6 (f) shows the rotor voltage and rotor current respectively. The results show that rotor voltage swell to $1.5 \mathrm{pu}$ soon after the wind gust ends. During loading conditions, large oscillations occur in the rotor winding which create additional heating in the rotor. PI controller tries to improve the transient response of voltage and current but does not overcome it. The sharp increase in current and phase imbalance occur in the rotor winding thereby affecting the power quality of wind power unit. The change in current in the rotor winding is higher than that of stator current. Fig. 8 (g) shows the destructive over voltage in DC link voltage to $2000 \mathrm{~V}$ which is beyond its nominal voltage of $1150 \mathrm{~V}$ for the period 0.08 to $0.32 \mathrm{sec}$ and then it reduces below the nominal value. can causes the failure of DC bus capacitor and may damage the PWM voltage source converter if it persists for several seconds and continuous operation of DFIG may be interrupted.

Fig. 6 (h) and 6 (i) show the DFIG active and reactive power. It can clearly be observed that aforementioned powers show zero output during the disturbance. As the disturbance is over at $0.08 \mathrm{sec}$, there is rise in demand occurs for both powers elements. During normal operation, the fluctuations in the DFIG power output is due to the wind gust. The active power output becomes less than nominal value of $10 \mathrm{MW}$ from 0.1 sec to 0.3 sec and then reduces significantly to very low value i.e. $2 \mathrm{MW}$ at $0.4 \mathrm{sec}$ due to the fall in rotor speed and stator and rotor currents in particular. Under loading condition, the voltage at PCC remains less than $1.0 \mathrm{pu}$. The variations in voltage is significantly witnessed during $0.35 \mathrm{sec}$ to $0.5 \mathrm{sec}$ as shown in Fig. 6 (j). The grid voltage remains unaffected by applying 100kW load at PCC as shown in Fig. 6 (k). 


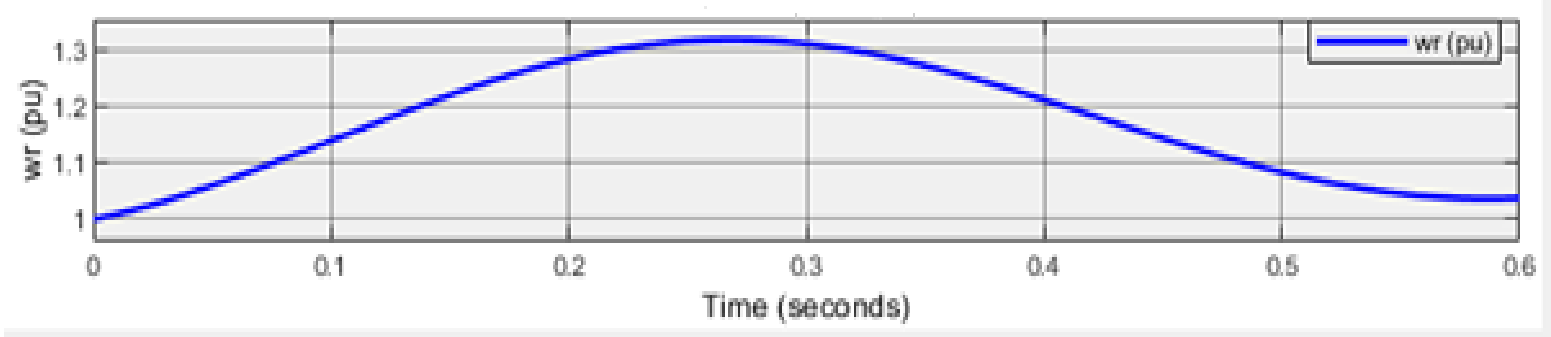

(a) Rotor speed (pu)

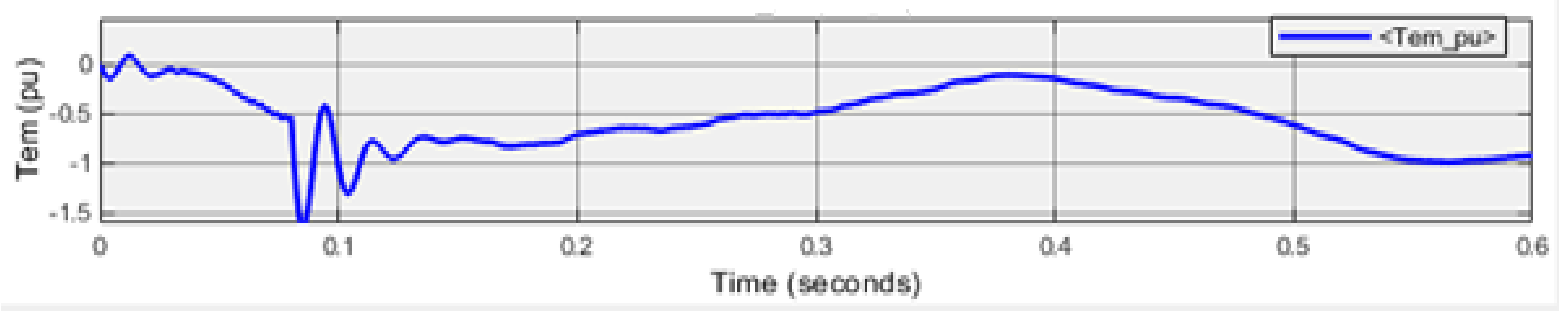

(b) Electromagnetic Torque (pu)

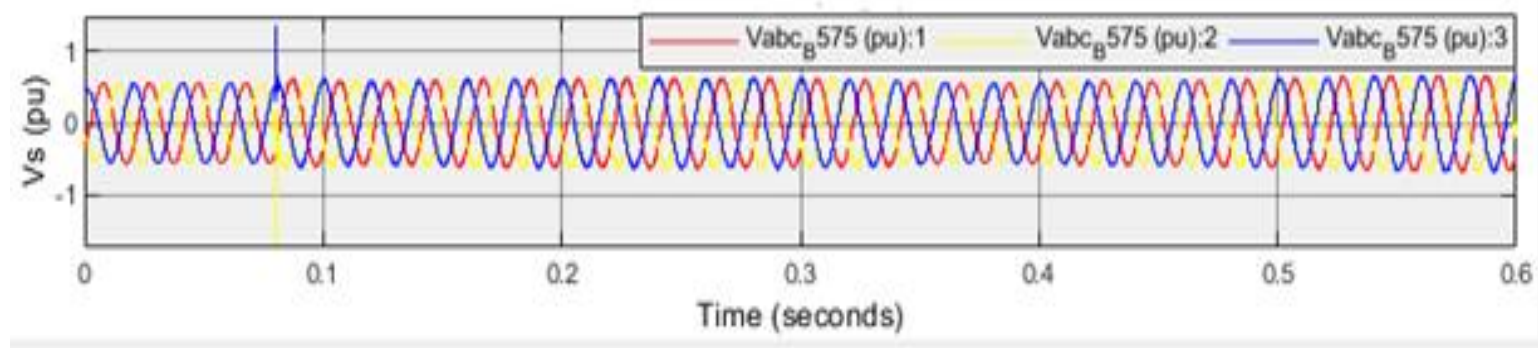

(c) Stator Voltage (pu)

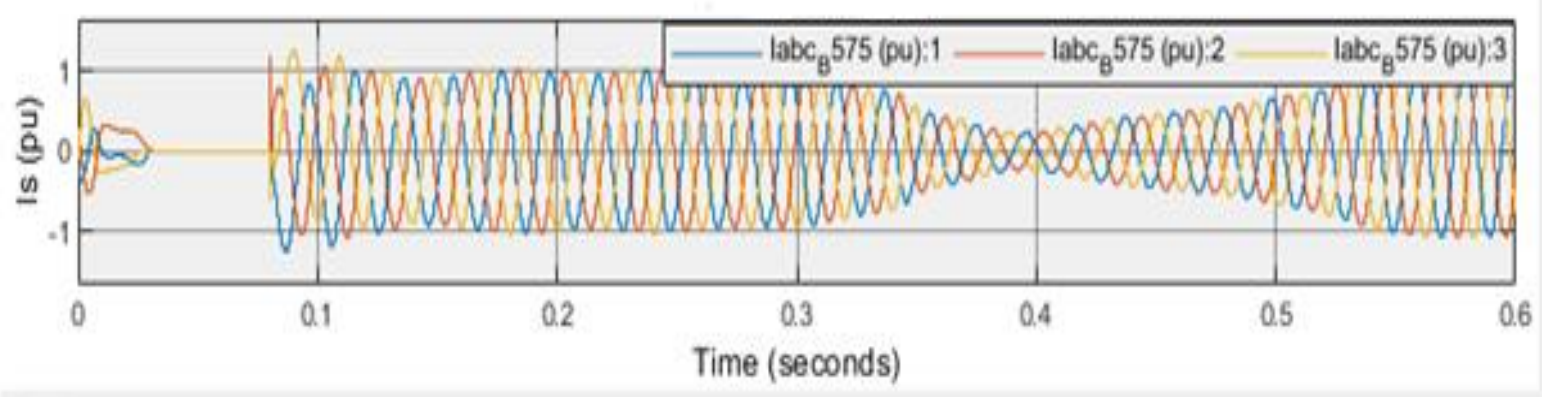

(d) Stator Current (pu)

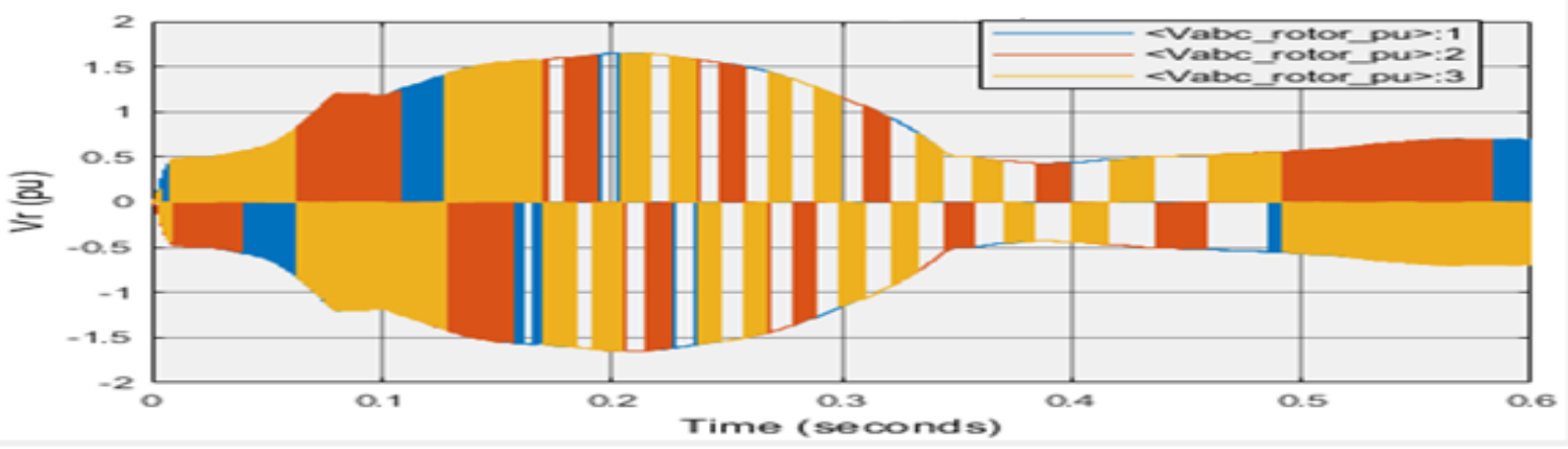

(e) Rotor Voltage (pu) 


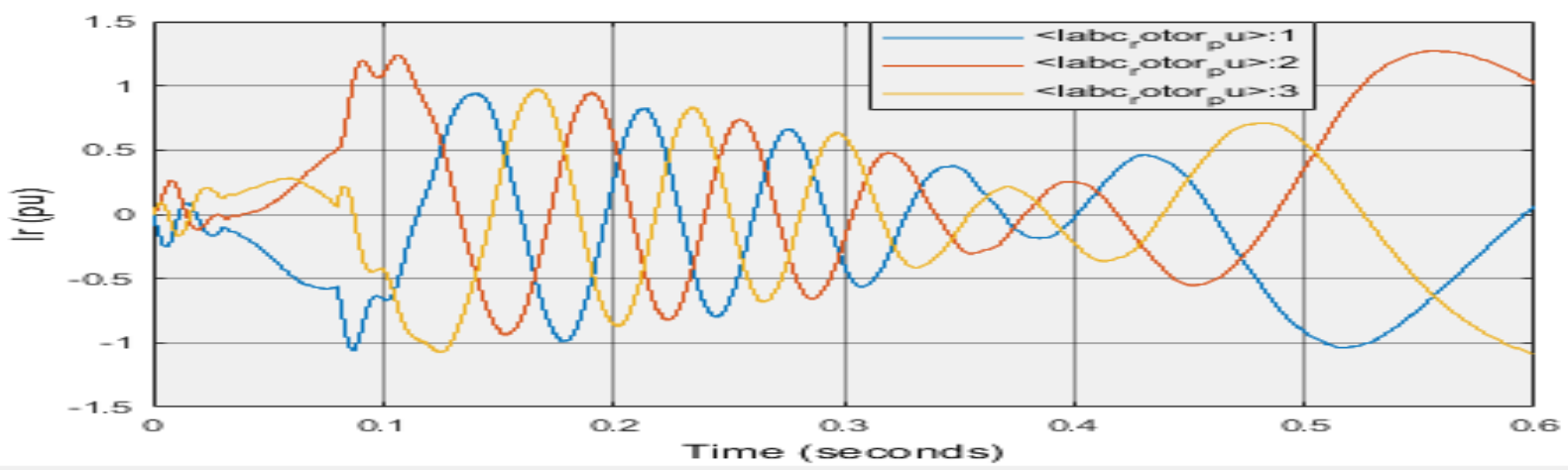

(f) Rotor Current (pu)

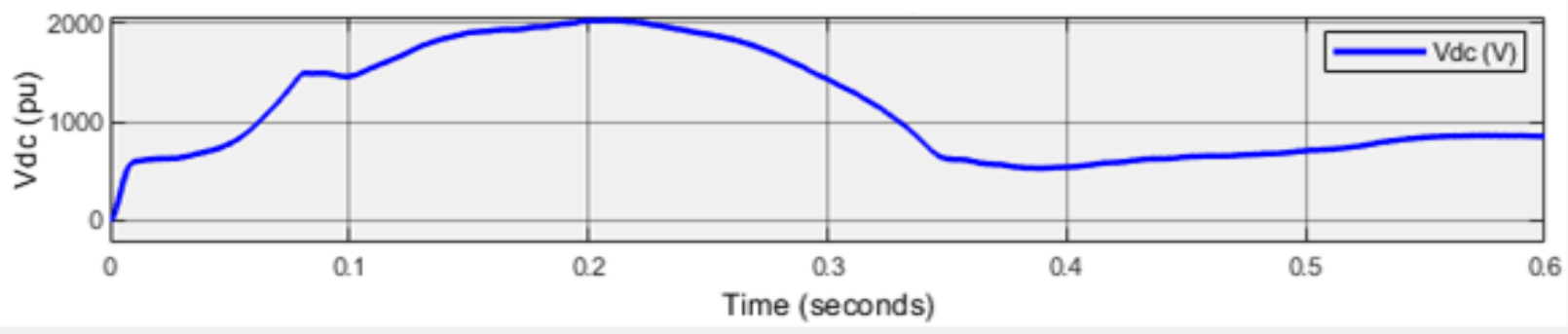

(g) DC Link Voltage (V)

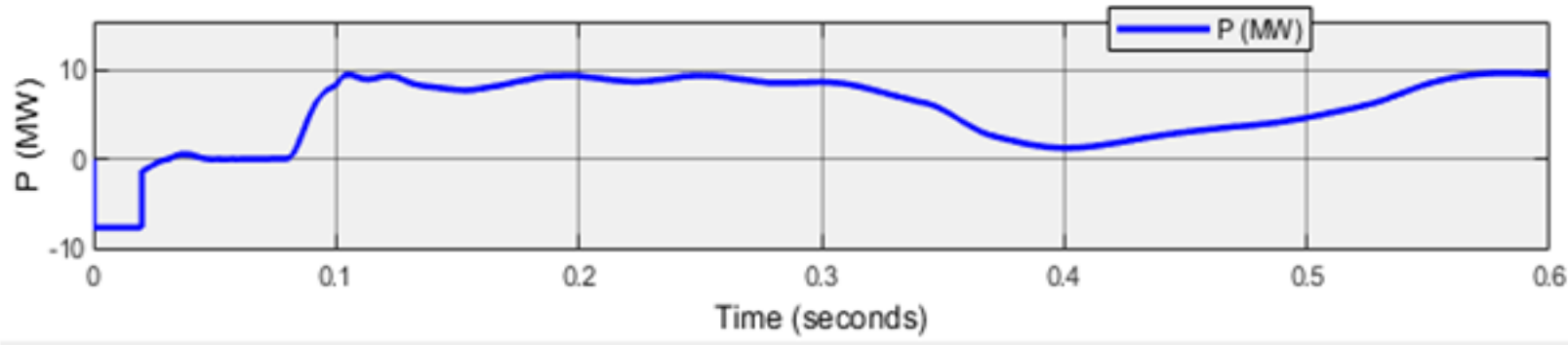

(h) Active Power (MW)

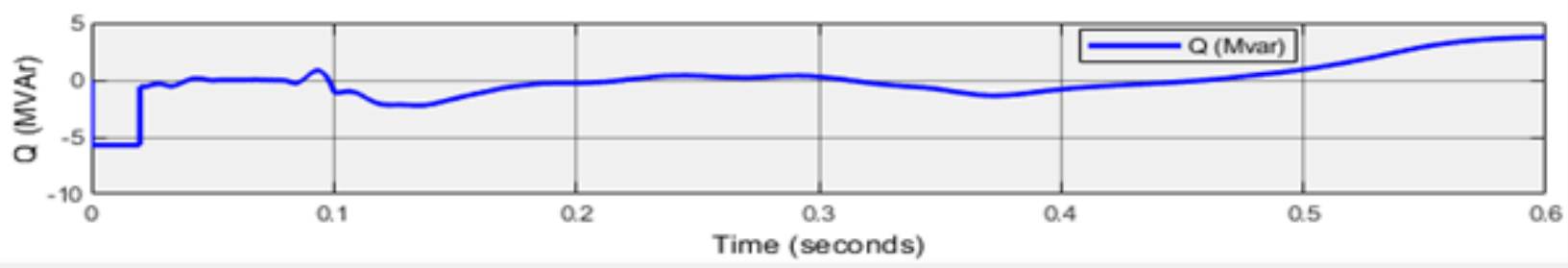

(i) Reactive Power (MVAr)

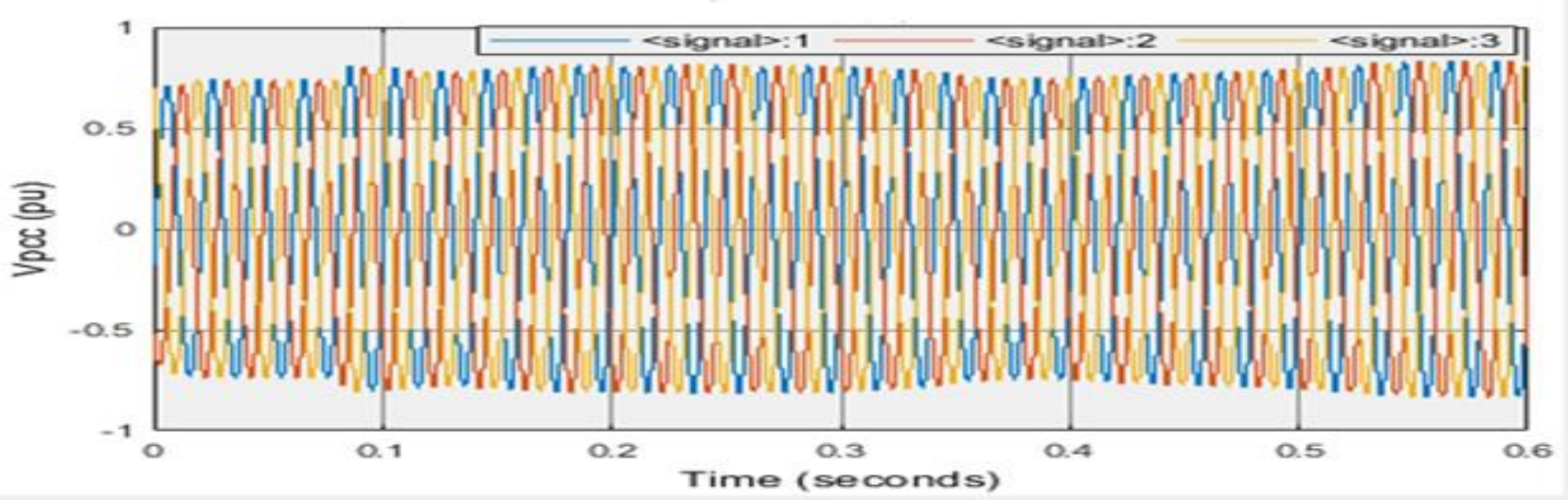

(j) Terminal Voltage at PCC (pu) 


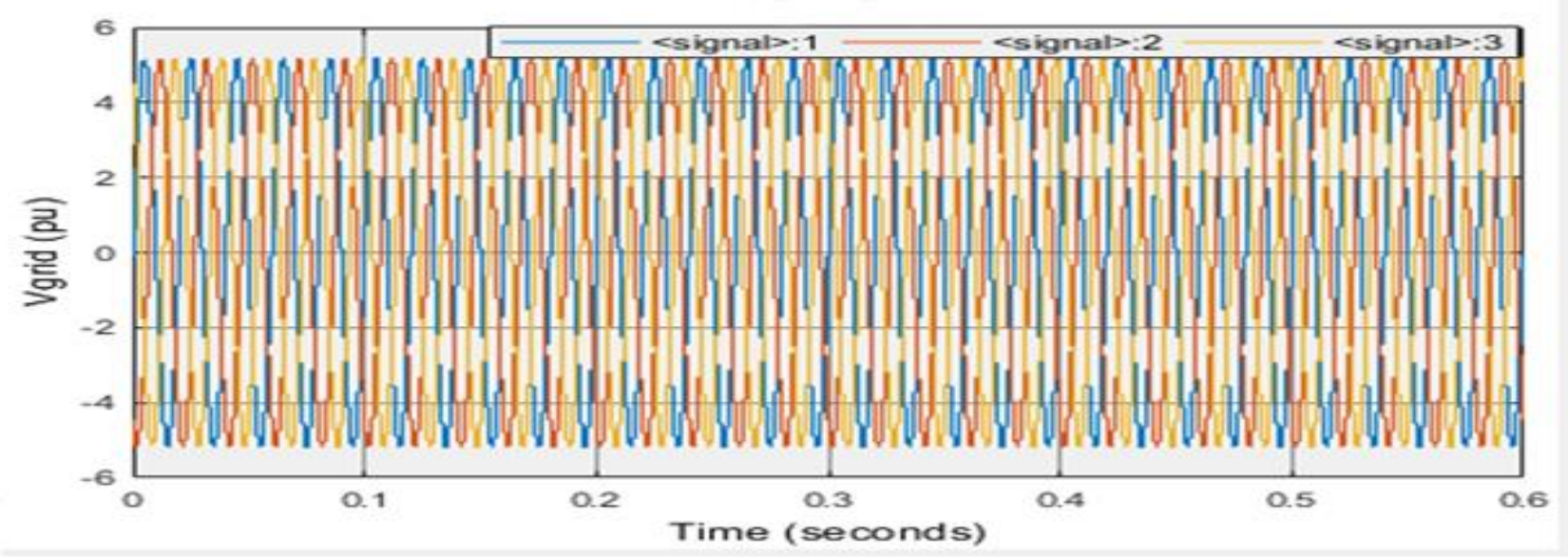

(k) Grid Voltage (pu)

Fig. 6 - Behavior of grid integrated DFIG model at $100 \mathrm{~kW}$ Load

The harmonic distortion under wind gust may be seen from waveform. The distortion is severe in the beginning and follows through during the wind gust for a period of $0.02 \mathrm{sec}$ to $0.08 \mathrm{sec}$ as shown in Fig. 7 (a). Later on, as stator and rotor current drop it develops current harmonic distortion for the second time thereby affecting the power quality. The spectrograph as depicted in Fig. 7 (b) suggests that $3^{\text {rd }}$ harmonic distortion is high due to power oscillations and it drastically reduces for higher harmonic order.

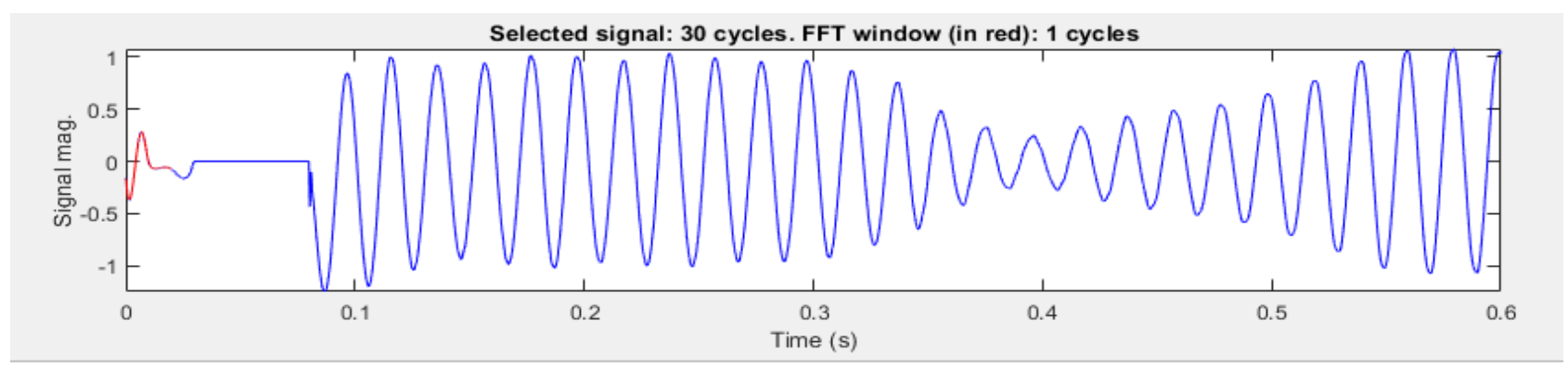

(a) Current Harmonic Distortion

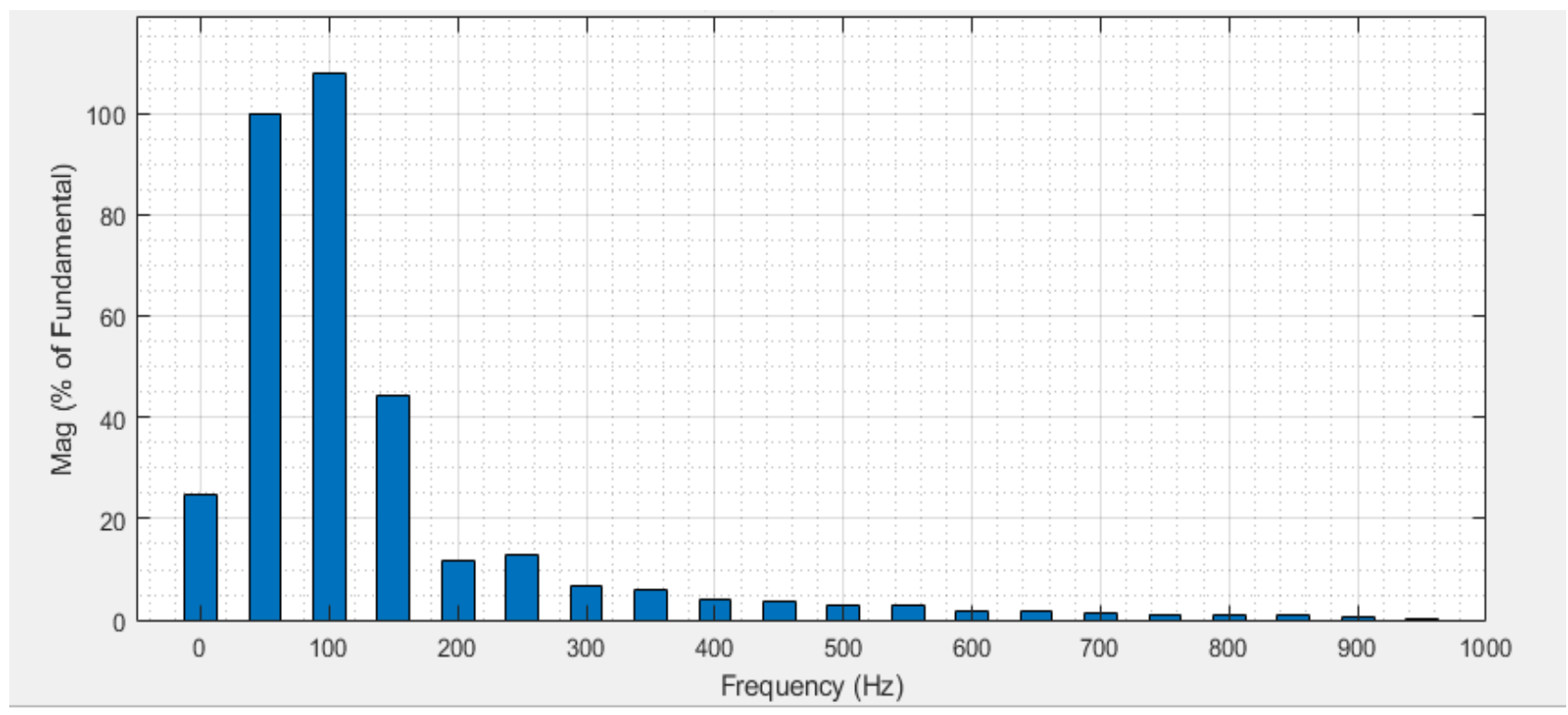

(b) Spectrograph of Current harmonic distortion

Fig. 7 - Behavior of current harmonic distortion in grid integrated DFIG 


\section{Conclusion}

The paper has presented the grid integrated DFIG under no load and with load at PCC. The PWM based VSC both at RSC and GSC along with conventional PI controller has been used to investigate the transient response of DFIG under wind gust for a period of $0.02 \mathrm{sec}$ to $0.08 \mathrm{sec}$. The rotor speed as well as electromagnetic torque with load are no longer different when compared with unloaded operating condition. However, the active power fluctuations with load were higher than that of no load at PCC. Moreover, the variation in stator and rotor current with load is much higher than that of unloaded condition. The high overvoltage in the DC link voltage was also observed which is very harmful for the RSC of DFIG. The grid voltage remains unaffected whether or not load is applied on it. Though, PI controllers reduced overshoot during the no load condition yet load applied at PCC disturbed the voltage profile of DFIG and increased the fluctuations in the active and reactive power. The harmonic distortion under wind gust have been observed in the model. The distortion is severe in the beginning and follows through during the wind gust. Consequently, voltage sag, voltage swell and current harmonic distortion takes places which affects the overall power quality in the variable speed WECS. This work can be extended with multilevel converters and applying robust controllers for smooth integration and minimizing the variations in the parameters of grid integrated DFIG.

\section{Acknowledgment}

This sincere effort is dedicated to my supervisor and co supervisor for their keen interaction to complete this task. The authors feel grateful to the directorate of post graduate studies and department of electrical engineering, MUET, Jamshoro for providing research funding and updated facilities for the compiling of the research paper.

\section{References}

[1] Mazhar H. Baloch, Ghulam S. Kaloi, Zubair A. Memon (2016) "Current scenario of wind energy in Pakistan Challenges and future perspectives" Elsevier Energy Reports pp. 201-210

[2] M.Boutoubat, L.Mokrani, M. Machmoum (2013) "Control of a wind energy conversion system equipped by a DFIG for active power generation and power quality improvement" Renewable Energy Volume 50, pp. 378386

[3] A. G. Abo-Khalil, S. Alyami, K. Sayed, A. Alhejji (2019) "Dynamic Modeling of Wind Turbines Based on Estimated Wind Speed under Turbulent Conditions". Energies, Vol. 12, No. 10

[4] Liserre, M., Cardenas, R., Molinas, M., \& Rodriguez, J.. (2011) "Overview of multi-MW wind turbines and wind parks". IEEE Transactions on Industrial Electronics, 58(4), pp. 1081-1095

[5] Mohseni, Mansour, and Syed M. Islam. (2011) "Transient control of DFIG-based wind power plants in compliance with the Australian grid code." IEEE Transactions on Power Electronics 27.6 pp. 2813-2824

[6] Jadhav, H. T., and Ranjit Roy. (2011) "A critical review on the grid integration issues of DFIG based wind farms." 10th International Conference on Environment and Electrical Engineering. IEEE

[7] Anees, Ahmed Sharique. (2012) "Grid integration of renewable energy sources: Challenges, issues and possible solutions." IEEE 5th India International Conference on Power Electronics (IICPE)

[8] V. S. Kumar, K. Reddy, and D. Thukaram, (2014) "Coordination of reactive power in grid-connected wind farms for voltage stability enhancement," IEEE Transactions on Power Systems, vol. 29, no. 5, pp. 2381-2390

[9] Ayodele, T. R., et al. (2012) "Challenges of grid integration of wind power on power system grid integrity: A review." International Journal of Renewable Energy and Research, vol. 2, No. 4

[10] Saqib, Muhammad A., and Ali Z. Saleem. (2015) "Power-quality issues and the need for reactive-power compensation in the grid integration of wind power." Renewable and Sustainable Energy Reviews 43 pp. 5164

[11] Cyrus Mehdipour Amin Hajizadeh, Iman Mehdipou (2016) "Dynamic modeling and control of DFIG-based wind turbines under balanced network conditions" Electrical Power and Energy Systems

[12] G.A. Ramos, M.A Rios, D.F Gomez, H. Palacios, L.A Posada (2017) "Doubly Fed Induction Generator Model for Power Quality Studies" IEEE workshop on Power Electronics and Power Quality Applications (PEPQA)

[13] Sangeetha.S , Mahalakshmi.R. Hemalatha.R (2015) "Power Quality Analysis of Grid Connected Wind Energy Conversion System under Varying Wind Speed Conditions with Synchronous Generator and Doubly Fed Induction Generator" International Journal of Applied Engineering Research ISSN 0973-4562 Vol. 10, No. 10

[14] Jie Ren Yang Wang Xian, Yong Xiao, Kai Liu (2019) "Response of Rotor Over-voltage In DFIG Based Wind Generator Under Recurring Voltage Sags "25th International Conference on Electricity Distribution Madrid

[15] Prasad, Deepak Kumar, K. Seethalekshmi, and Preeti Verma. (2019) "Analysis of Small Signal and Transient Stability under the Penetration of DFIG Integrated Wind Energy Conversion System." 2019 International Conference on Electrical, Electronics and Computer Engineering (UPCON). IEEE

[16] Adetokun, B. B., Muriithi, C. M., \& Ojo, J. O. (2020) "Voltage stability assessment and enhancement of power grid with increasing wind energy penetration" International Journal of Electrical Power \& Energy Systems, 120, 105988

[17] Ghulam Sarwar Kaloi, Mazhar Hussain Baloch, Mahesh Kumar, Dur Muhammad Soomro, Sohaib Tahir Chauhdary , Ali Asghar Memon and Dahaman Ishak (2019) “ An LVRT Scheme for Grid Connected DFIG Based WECS Using State Feedback Linearization Control Technique " Electronics 
[18] M Abozekry, D S M Osheba, H Z Azazi and S M Osheba (2019) “Performance enhancement of a DFIG wind energy conversion system using phase advanced network" IOP Conference Series: Materials Science and Engineering

[19] Abderraouf BOUMASSATA, Djallel KERDOUN (2014) "Modeling, Simulation and Control of Wind Energy Conversion System based on Doubly Fed Induction Generator and Cycloconverter" Advances in Electrical and Computer Engineering, Volume 14, No. 2

[20] F. Taveiros, L. Barros, and F. Costa, (2015) "Back-to-back converter state-feedback control of DFIG (doublyfed induction generator)-based wind turbines," Energy, vol. 89, pp. 896-906

[21] Ahmad A. Salah; D. G. Dorrell (2019) “Operating Induction Machine in DFIG Mode Including Rotor Asymmetry” 2019 AUPEC / Rob Mech / PRASA Conference Bloemfontein, South Africa

[22] Mohammed Fdaili, Ahmed Essadki, Mohamed Nadour, Tamou Nasser (2019) "Control and Optimization of a Wind Energy Conversion System Based on Doubly-Fed Induction Generator Using Nonlinear Control Strategies" IJRER, Vol. 9, No. 1

[23] B. Jain, S. Jain, and R. Nema, (2015) "Control strategies of grid interfaced wind energy conversion system: An overview," Renewable and Sustainable Energy Reviews, vol. 47, pp. 983-996

[24] J. Hu, H. Xu, and Y. He, (2012) "Coordinated control of DFIG's RSC and GSC under generalized unbalanced and distorted grid voltage conditions," IEEE Transactions on Industrial Electronics, vol. 60, pp. 2808-2819

[25] O. Mahela and A. Shaik, (2016) "Power quality improvement in distribution network using DSTATCOM with battery energy storage system,” International Journal of Electrical Power \& Energy Systems, vol. 83, pp. 229240

[26] S. Kulkarni and P. shingara, (2016) "A review on power quality challenges in renewable energy grid integration", IJCET, Vol. 6, No. 5

[27] S. Ruksana, S. Singh, A. Goswami, and N. Sinha, (2018) "Recent Challenges for Power Quality Impacts on Grid Integrated Wind Energy System: A Review," in 2018 Second International Conference on Intelligent Computing and Control Systems pp. 420-426, (ICICCS)

[28] J. Ndirangu, J. Nderu, A. Muhia, and C. Maina, (2018) "Power quality challenges and mitigation measures in grid integration of wind energy conversion systems," IEEE International Energy Conference (ENERGYCON), pp. 1-6 